\title{
Unravelling the Scientific Debate on How to Address Wolf-Dog Hybridization in Europe
}

\section{OPEN ACCESS}

Edited by:

David Jack Coates,

Department of Biodiversity,

Conservation and Attractions

(DBCA), Australia

Reviewed by:

Mirko Di Febbraro,

University of Molise, Italy

Jouni Aspi,

University of Oulu, Finland

*Correspondence:

Valerio Donfrancesco

donfrancesco.valerio@gmail.com

tThese authors have contributed equally to this work

Specialty section:

This article was submitted to

Conservation

a section of the journal

Frontiers in Ecology and Evolution

Received: 13 November 2018 Accepted: 30 April 2019

Published: 21 May 2019

Citation:

Donfrancesco V, Ciucci P, Salvatori V, Benson D, Andersen LW, Bassi E, Blanco JC, Boitani L, Caniglia R, Canu A, Capitani C, Chapron G. Czarnomska SD, Fabbri E, Galaverni M, Galov A, Gimenez O, Godinho R, Greco C, Hindrikson M, Huber D, Hulva P, Jedrzejewski W, Kusak J, Linnell JDC, Llaneza L,

López-Bao JV, Männil P, Marucco F, Mattioli L, Milanesi P, Milleret C, Mysłajek RW, Ordiz A, Palacios V, Pedersen HC, Pertoldi C, Pilot M, Randi E, Rodríguez A, Saarma U, Sand H, Scandura M, Stronen AV, Tsingarska E and Mukherjee N (2019) Unravelling the Scientific Debate on

How to Address Wolf-Dog Hybridization in Europe.

Front. Ecol. Evol. 7:175.

doi: 10.3389/fevo.2019.00175
Valerio Donfrancesco ${ }^{1 *}$, Paolo Ciucci ${ }^{2 \dagger}$, Valeria Salvatori ${ }^{3}$, David Benson ${ }^{4}$, Liselotte Wesley Andersen ${ }^{5}$, Elena Bassi ${ }^{6}$, Juan Carlos Blanco ${ }^{7}$, Luigi Boitani ${ }^{2}$, Romolo Caniglia ${ }^{8}$, Antonio Canu ${ }^{6}$, Claudia Capitani ${ }^{9}$, Guillaume Chapron ${ }^{10}$, Sylwia D. Czarnomska ${ }^{11}$, Elena Fabbri ${ }^{8}$, Marco Galaverni ${ }^{12}$, Ana Galov ${ }^{13}$, Olivier Gimenez ${ }^{14}$, Raquel Godinho ${ }^{15}$, Claudia Greco ${ }^{8}$, Maris Hindrikson ${ }^{15,16}$, Djuro Huber ${ }^{17}$, Pavel Hulva ${ }^{18,19}$, Włodzimierz Jedrzejewski ${ }^{20}$, Josip Kusak ${ }^{17}$, John D. C. Linnell ${ }^{21}$, Luis Llaneza ${ }^{22}$, José Vicente López-Bao ${ }^{23}$, Peep Männil ${ }^{24}$, Francesca Marucco ${ }^{25}$, Luca Mattioli ${ }^{26}$, Pietro Milanesi ${ }^{27}$, Cyril Milleret ${ }^{28}$, Robert W. Mysłajek ${ }^{29}$, Andres Ordiz ${ }^{28}$, Vicente Palacios ${ }^{30}$, Hans Christian Pedersen ${ }^{21}$, Cino Pertoldi ${ }^{31}$, Malgorzata Pilot ${ }^{32}$, Ettore Randi ${ }^{33,34}$, Alejandro Rodríguez ${ }^{35}$, Urmas Saarma ${ }^{16}$, Håkan Sand ${ }^{10}$, Massimo Scandura ${ }^{6}$, Astrid Vik Stronen ${ }^{36,37}$, Elena Tsingarska ${ }^{38}$ and Nibedita Mukherjee ${ }^{1,39 \dagger}$

${ }^{1}$ Centre for Ecology and Conservation, College of Life and Environmental Sciences, University of Exeter, Penryn, United Kingdom, ${ }^{2}$ Department of Biology and Biotechnologies, Università di Roma La Sapienza, Rome, Italy, ${ }^{3}$ stituto di Ecologia Applicata, Rome, Italy, ${ }^{4}$ Environment and Sustainability Institute, University of Exeter, Penryn, United Kingdom, ${ }^{5}$ Department of Bioscience, Aarhus University, Aarhus, Denmark, ${ }^{6}$ Department of Veterinary Medicine, University of Sassari, Sassari, Italy, ${ }^{7}$ Conservation Biology Consultants, Madrid, Spain, ${ }^{8}$ Unit for Conservation Genetics (BIO-CGE), Department for the Monitoring and Protection of the Environment and for Biodiversity Conservation, Italian Institute for Environmental Protection and Research, Bologna, Italy, ${ }^{9}$ Department of Environment and Geography, University of York, York, United Kingdom, ${ }^{10}$ Department of Ecology, Grimsö Wildlife Research Station, Swedish University of Agricultural Sciences, Riddarhyttan, Sweden, ${ }^{11}$ Institute of Biochemistry and Biophysics, Polish Academy of Sciences, Warsaw, Poland, ${ }^{12}$ Conservation Area, WWF Italy, Rome, Italy, ${ }^{13}$ Faculty of Science, University of Zagreb, Zagreb, Croatia, ${ }^{14}$ CEFE, CNRS, Université Paul-Valéry, Montpellier, France, ${ }^{15}$ Centro de Investigação em Biodiversidade e Recursos Genéticos, Universidade do Porto, Porto, Portugal, ${ }^{16}$ Department of Zoology, Institute of Ecology and Earth Sciences, University of Tartu, Tartu, Estonia, ${ }^{17}$ Department of Biology, Faculty of Veterinary Medicine, University of Zagreb, Zagreb, Croatia, ${ }^{18}$ Department of Zoology, Charles University, Prague, Czechia, ${ }^{19}$ Life Science Research Centre, University of Ostrava, Ostrava, Czechia, ${ }^{20}$ Centro de Ecología, Instituto Venezolano de Investigaciones Científicas, Caracas, Venezuela, ${ }^{21}$ Norwegian Institute for Nature Research, Trondheim, Norway, ${ }^{22}$ Asesores en Recursos Naturales, Lugo, Spain, ${ }^{23}$ Research Unit of Biodiversity (UO/CSIC/PA), Oviedo University, Mieres, Spain, ${ }^{24}$ Widdlife Department, Estonian Environment Agency, Tartu, Estonia, ${ }^{25}$ Centro Grandi Carnivori, Ente di Gestione Aree Protette Alpi Marittime, Valdieri, Italy, ${ }^{26}$ Regione Toscana, Settore Attività Faunistico Venatoria, Pesca Dilettantistica, Pesca in Mare, Arezzo, Italy, ${ }^{27}$ Monitoring Department, Swiss Ornithological Institute, Sempach, Switzerland, ${ }^{28}$ Faculty of Environmental Sciences and Natural Resource Management, Norwegian University of Life Sciences, Ås, Norway, ${ }^{29}$ Faculty of Biology, Institute of Genetics and Biotechnology, University of Warsaw, Warszawa, Poland, ${ }^{30}$ Iberian Wolf Research Team, Oviedo, Spain, ${ }^{31}$ Department of Chemistry and Bioscience, Aalborg University, Aalborg, Denmark, ${ }^{32}$ School of Life Sciences, University of Lincoln, Lincoln, United Kingdom, ${ }^{33}$ Department of Biological, Geological and Environmental Sciences, University of Bologna, Bologna, Italy, ${ }^{34}$ Department of Chemistry and Bioscience, Faculty of Engineering and Science, University of Aalborg, Aalborg, Denmark, ${ }^{35}$ Department of Conservation Biology, Estación Biológica de Doñana-Spanish National Research Council, Sevilla, Spain, ${ }^{36}$ Department of Biology, Biotechnical Faculty, University of Ljubljana, Ljubljana, Slovenia, ${ }^{37}$ Department of Biotechnology and Life Sciences, Insubria University, Varese, Italy, ${ }^{38}$ Balkani Wildlife Society, Sofia, Bulgaria, ${ }^{39}$ Department of Zoology, University of Cambridge, Cambridge, United Kingdom

Anthropogenic hybridization is widely perceived as a threat to the conservation of biodiversity. Nevertheless, to date, relevant policy and management interventions are unresolved and highly convoluted. While this is due to the inherent complexity of the issue, we hereby hypothesize that a lack of agreement concerning management goals and approaches, within the scientific community, may explain the lack of social awareness 
on this phenomenon, and the absence of effective pressure on decision-makers. By focusing on wolf $x$ dog hybridization in Europe, we hereby (a) assess the state of the art of issues on wolf $x$ dog hybridization within the scientific community, (b) assess the conceptual bases for different viewpoints, and (c) provide a conceptual framework aiming at reducing the disagreements. We adopted the Delphi technique, involving a three-round iterative survey addressed to a selected sample of experts who published at Web of Science listed journals, in the last 10 years on wolf $x$ dog hybridization and related topics. Consensus was reached that admixed individuals should always be defined according to their genetic profile, and that a reference threshold for admixture (i.e., q-value in assignment tests) should be formally adopted for their identification. To mitigate hybridization, experts agreed on adopting preventive, proactive and, when concerning small and recovering wolf populations, reactive interventions. Overall, experts' consensus waned as the issues addressed became increasingly practical, including the adoption of lethal removal. We suggest three non-mutually exclusive explanations for this trend: (i) value-laden viewpoints increasingly emerge when addressing practical issues, and are particularly diverging between experts with different disciplinary backgrounds (e.g., ecologists, geneticists); (ii) some experts prefer avoiding the risk of potentially giving carte blanche to wolf opponents to (illegally) remove wolves, based on the wolf $x$ dog hybridization issue; (iii) room for subjective interpretation and opinions result from the paucity of data on the effectiveness of different management interventions. These results have management implications and reveal gaps in the knowledge on a wide spectrum of issues related not only to the management of anthropogenic hybridization, but also to the role of ethical values and real-world management concerns in the scientific debate.

Keywords: conservation, delphi technique, genetic admixture, introgression, lethal removal, management, ethics, values in science

\section{INTRODUCTION}

Hybridization is a biological process defined as the intermixing of two distinct yet closely related taxa, which may deeply affect the genetic make-up, long-term survival and evolution of the species (Gompert and Buerkle, 2016). While natural hybridization is associated with several positive evolutionary outcomes (e.g., genetic rescue, Brennan et al., 2014; speciation, Lavrenchenko and Bulatova, 2016), anthropogenic hybridization is widely perceived as a potential threat for species conservation. Anthropogenic hybridization is defined as hybridization facilitated by human impact and interference, either on purpose or accidentally, that often results in the elimination of barriers between otherwise distinct populations, which may go through the processes of genetic admixing and loss of evolutionary adaptation (Rhymer and Simberloff, 1996; Allendorf et al., 2001). Cases of anthropogenic hybridization are well-documented in canids (Gottelli et al., 1994; Elledge et al., 2008; Khosravi et al., 2013; Freedman et al., 2014; vonHoldt et al., 2016), including interbreeding between wolves (Canis lupus) and dogs (C. l. familiaris; Randi, 2008; Leonard et al., 2014). In the European continent, episodes of wolf $\mathrm{x}$ dog hybridization (hereafter: $\mathrm{WDH}$ ) have been detected in several wolf populations (Vilà et al., 2003; Godinho et al., 2011; Randi, 2011; Hindrikson et al.,
2012; Kusak et al., 2018), thus offering an excellent case study for exploring anthropogenic hybridization challenges and solutions.

While WDH has likely occurred on multiple occasions since dog domestication (Freedman et al., 2014; Fan et al., 2016; Pilot et al., 2018), there is concern in the scientific community that increased rates in the Anthropocene may represent a rising threat to the conservation of wolf populations (Boitani, 2003; Randi, 2008). Specifically, because hybrids between wolves and dogs are usually fertile, WDH may threaten wolf populations with different extents of genomic introgression up to complete admixture and genomic extinction (i.e., Type 5 and Type 6 introgressive hybridization, respectively, sensu Allendorf et al., 2001; Figure 1). The problems with hybridization between a domestic species and its wild ancestor are: (i) domestic forms are often present in much higher densities than wild forms, and (ii) the domestication process has been associated with intensive selection for traits that may be disadvantageous in the wild. Hence, several researchers and conservationists have urged management authorities to address the WDH issue (cf., notably Allendorf et al., 2001; Hindrikson et al., 2017). A recent review on the status of wolf populations in Europe, identified interactions with domestic dogs leading to disease transfer and/or hybridization amongst the major threats common to almost all wolf populations (Hindrikson et al., 2017). Notably, 
hybridization was brought forth as one of the significant gaps in the current knowledge, and the initiation of a Europewide scientific project on WDH was proposed to fill this gap (Hindrikson et al., 2017).

However, management of WDH is difficult for several reasons. First, due to the technical problem of identification of hybrid individuals (VonHoldt et al., 2011; Lorenzini et al., 2014; Randi et al., 2014; Godinho et al., 2015), the scientific debate has lagged behind contemporary management. While hybridization is increasingly detectable through the advent of genetic markers, phenotypic cues of hybridization are less reliable and more difficult to interpret (e.g., Hindrikson et al., 2012; Galaverni et al., 2017). In addition, even though first generations hybrids (F1s), F2s, and first- and second-generation backcrosses (B1s, B2s) may be genetically conspicuous enough to be reliably identified (Lorenzini et al., 2014; Randi et al., 2014; Godinho et al., 2015), further generations of backcrosses into the parental wolf population are increasingly difficult to detect. Under these conditions, the risks of erroneously classifying an admixed individual as a wolf (i.e., Type II error) are substantial and higher than the complementary error (i.e., erroneously classifying a wolf as an admixed individual, or Type I error; Lorenzini et al., 2014; Randi et al., 2014; Galaverni et al., 2017).

Second, global policy regarding the management of hybridization remains largely unresolved to date. In the United States, a first attempt at developing a clear policy for the mitigation of anthropogenic hybridization was proposed in 1996 (US Fish and Wildlife Service, 1996). However, to date, it remains neither accepted nor rejected (Wayne and Shaffer, 2016). Similarly, in Canada, the "Species at Risk Act" (SARA) does not address the legal status of admixed individuals (Piett et al., 2015). In Europe, directions by the two main legal instruments governing biodiversity conservation (i.e., the EU Council Directive 92/43/EEC and the Bern Convention) are generally unclear on how to manage admixed individuals (Trouwborst, 2014), though recent improvements in the WDH context have occurred. Specifically, EU Member States are now required to implement effective management and monitoring of WDH to decrease the impact of hybridization on wolf populations, including removal of hybrids ${ }^{1}$, as originally recommended by the Bern Convention (i.e., Recommendation no. 173, 2014). Moreover, the management of hybrids was specifically delegated to official agencies only (Recommendation no. 173, 2014, of the Bern Convention) to avoid legal loopholes justifying the killing of protected taxa (Trouwborst, 2014; Peltola and Heikkilä, 2018). Such fragmentation of European legislation into separate facets underscores its legal complexity and articulation.

Third, even though increasing rates of hybridization are being reported in certain wolf populations and local situations (e.g., Italy: Caniglia et al., 2013; Galaverni et al., 2017; Portugal: Pacheco et al., 2017; Croatia: Kusak et al., 2018), some researchers contest the idea that WDH is a serious conservation concern or even that anthropogenic hybridization represents an issue at all (Rohwer and Marris, 2015; Lescureux, 2018). Concurrently,

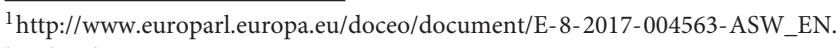
html? redirect conflicting ideas on the management goals for WDH and other types of anthropogenic hybridization further reinforce the debate within the scientific community. On one hand, some researchers suggest managing admixed individuals on the bases of their ecological function (i.e., the concept of ecological surrogates; Daniels and Corbett, 2003; Glen, 2010; Fitzpatrick et al., 2015; Jackiw et al., 2015; van Eeden et al., 2018), increased evolutionary potential (Fitzpatrick et al., 2015; Jackiw et al., 2015; Wayne and Shaffer, 2016), or "cultural function" (Daniels and Corbett, 2003; Glen, 2010; van Eeden et al., 2018). On the other hand, all these ideas contradict the most influential guidelines on anthropogenic hybridization, which rather recommend preserving the genetic integrity of wild species (i.e., Allendorf et al., 2001).

Fourth, diverging ethical values may hinder the implementation of certain management interventions to manage anthropogenic hybridization, especially if this entails lethal removal (Way and Bruskotter, 2012; Lewis et al., 2017). Although lethal removal has been widely used in conservation (Wallach et al., 2015), changing societal values might represent an increasing barrier to its implementation (Manfredo et al., 2003; Lewis et al., 2017; Lute et al., 2018). There is also opposition toward addressing the mitigation of anthropogenic hybridization, arising from moral and ethical values concerning the management of hybrids. For instance, von Essen and Allen (2016) suggest that it would be "unconscionable" to not recognize the rights of wolf $\mathrm{x}$ dog hybrids, as we have sole responsibility for their existence, and there would be no justifiable basis for having resentment against them. These authors sought an amendment to the EU Council Directive 92/43/EEC to explicitly recognize hybrids in legal frameworks (von Essen and Allen, 2016). While all of the above rests purely on theoretical grounds, wildlife practitioners and managers dealing with practical issues on a daily basis follow different protocols (e.g., Vilà et al., 2003; Godinho et al., 2015), and believe such arguments are neither adequate nor practical to deal with reality, though counter-arguments to this have been raised (e.g., Nelson et al., 2016).

The mitigation of anthropogenic hybridization generally involves three types of interventions: preventive, proactive, and reactive interventions (Table 1). In Europe, mitigation of WDH is informed by legally binding supranational legislation, management guidelines endorsed by the European Commission (developed by scientific and expert groups with stakeholder input, but not legally binding), and peer-reviewed publications. There are three critical facets to note here:

1. European conservation legislation (i.e., the EU Council Directive 92/43/EEC, and Recommendation $\mathrm{nr}$ 173, 2014 of the Bern Convention) requires that $\mathrm{WDH}$ be mitigated through effective management;

2. The European population level management guidelines ${ }^{2,3}$ recommend implementing reactive interventions whenever possible;

\footnotetext{
${ }^{2} \mathrm{http}$ //ec.europa.eu/environment/nature/conservation/species/carnivores/pdf/ guidelines_for_population_level_management.pdf

${ }^{3}$ http://ec.europa.eu/environment/nature/conservation/species/carnivores/pdf/ key_actions_large_carnivores_2015.pdf
} 


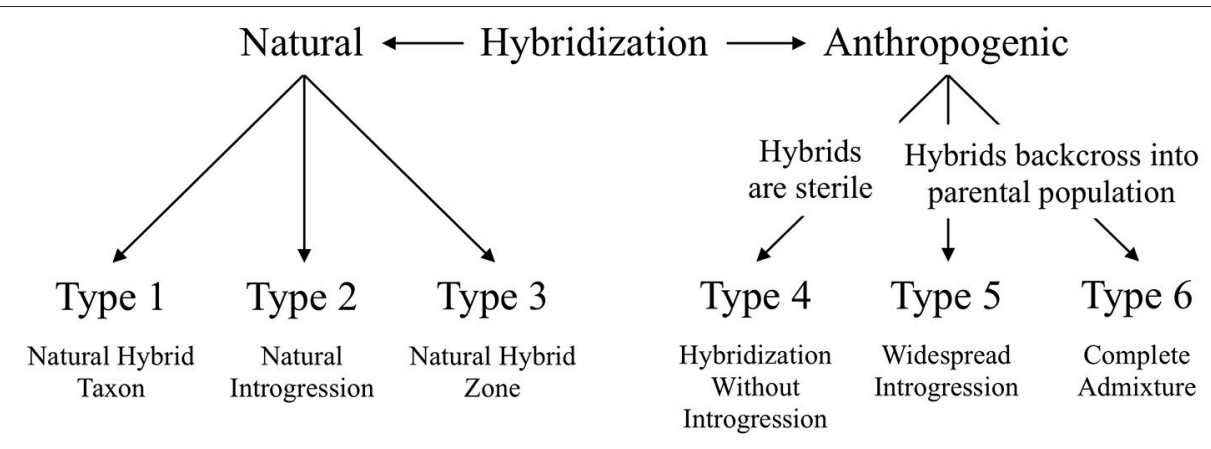

FIGURE 1 | A framework to categorize types of hybridization according to a seminal paper by Allendorf et al. (2001). Types 1-3 are forms of natural hybridization, and the resulting taxa should be eligible for conservation. Types 4-6 are forms of anthropogenic hybridization, and the three categories have different consequences from a conservation perspective.

TABLE 1 | Key strategies, and corresponding management interventions, available to address the mitigation of anthropogenic hybridization (adapted for a case study on wolf $\times$ dog hybridization).

\begin{tabular}{lll}
\hline $\begin{array}{l}\text { Intervention } \\
\text { strategy }\end{array}$ & Definition & $\begin{array}{l}\text { Practical approach in WDH } \\
\text { contexts }\end{array}$ \\
\hline Preventive & $\begin{array}{l}\text { Anticipating change before } \\
\text { it happens }\end{array}$ & $\begin{array}{l}\text { Community engagement and } \\
\text { education to decrease the } \\
\text { number of free-ranging dogs }\end{array}$ \\
Proactive & $\begin{array}{l}\text { Taking action by causing } \\
\text { change and not only } \\
\text { reacting to change when it } \\
\text { happens }\end{array}$ & $\begin{array}{l}\text { Removal of free-ranging dogs, } \\
\text { and reduction of other factors } \\
\text { facilitating WDH (e.g., habitat } \\
\text { restoration, addressing } \\
\text { poaching) }\end{array}$ \\
& $\begin{array}{l}\text { Responding to a change } \\
\text { after it happened }\end{array}$ & $\begin{array}{l}\text { The active management of } \\
\text { admixed individuals as to reduce } \\
\text { their prevalence in the parental } \\
\text { wolf population (i.e., capture, } \\
\text { captivity, sterilization and release, } \\
\text { or lethal removal) }\end{array}$ \\
\hline
\end{tabular}

Definition according to Cambridge Dictionary (www. dictionary.cambridge.org).

3. Part of the scientific community at the European scale is skeptical about adopting reactive interventions, because they are believed to be trivial without pervasive proactive interventions (cf., notably Lorenzini et al., 2014), and because their effectiveness is thought to be limited (e.g., Godinho et al., 2015; Pacheco et al., 2017).

To our knowledge, there are no experimental studies comparing the effectiveness of the three types of interventions (i.e., preventive, proactive, and reactive), in WDH contexts. This dearth of empirical studies may result from the poor implementation of $\mathrm{WDH}$ interventions at different national levels. In Europe, some countries address WDH in their local laws and/or management plans (e.g., Germany, Luxembourg, Norway, Poland, Slovakia, Slovenia, Spain, Switzerland), while other countries (e.g., Albania, Austria, Bosnia, and Herzegovina, Bulgaria, Croatia, France, Greece, Italy, Lithuania, Macedonia, Portugal, Romania, Serbia) do not have any specific strategy (Salvatori and Ciucci, 2018). When interventions are not addressed in national or federal programs, it may be problematic to implement them purely for evaluation or research purposes. In case of reactive interventions, this issue is further complicated due to the legal status of wolves according to the Bern Convention and the EU Council Directive 92/43/EEC, and any management intervention additionally interweaves with the animal welfare issues addressed in the Directive 2010/63/EU. To our knowledge, the only experimental studies published on the effectiveness of interventions meant to mitigate and reduce occurrence of anthropogenic hybridization in wild canids have been conducted in North America, as part of a federal program to control introgression of red wolves (C. rufus) by coyotes (C. latrans; Gese and Terletzky, 2015; Gese et al., 2015). The findings of these studies suggest that adopting lethal removal in conjunction with sterilization and release of both coyotes and introgressed individuals can be an effective strategy. Particularly, the authors emphasize that genetically testing wild-born litters is a key management intervention to remove hybrids before they reach breeding age (Gese et al., 2015).

Management of $\mathrm{WDH}$ is a complex issue, intermingling biological, technical, social, ethical and legal issues, which currently remain largely unaddressed and unresolved in the conservation community. Greater consensus among scientists dealing with management issues may be key to effectively raise social awareness (Lewandowsky et al., 2013; Aklin and Urpelainen, 2014), exert coordinated pressure on decision-makers (de Kerckhove et al., 2015), and ultimately implement interventions.

The acceptance of the public (e.g., of various groups of stakeholders) of management interventions is crucial to the success of any wildlife conservation strategy (Fix et al., 2010; Teel and Manfredo, 2010). This is especially true when dealing with highly charismatic flagship species such as the wolf, or with domestic/companion animals such as dogs that have extremely complex relationships with humans. In particular, justifying the implementation of reactive interventions to the public, comprising lethal removal (Way and Bruskotter, 2012; Lewis et al., 2017), may be an arduous task for wildlife managers and politicians alike without strong scientific consensus supporting this course of action. 
Here, we hypothesize that the technical, social, ethical, and legal dimensions of the WDH issue may affect each other and generate fragmented opinions within the scientific community and, in particular, among experts of different expertise and educational backgrounds. The debate may then be strongly yet cryptically value-laden, with disagreement possibly explaining why science-based management of anthropogenic hybridization (generally) lags behind compared to other conservation issues (e.g., climate change; van der Linden et al., 2015) in developing a common view and crafting effective management criteria and protocols.

Given the above, our study specifically aims to:

(a) Assess the current discourse on anthropogenic hybridization, with WDH as a specific case study;

(b) Disentangle whether scientific disagreement emerges from technical uncertainties or value-laden grounds;

(c) Provide a conceptual framework useful to reduce disagreement and uncertainties within the scientific community in dealing with WDH.

\section{METHODS}

We used the expert-based, anonymous, iterative Delphi technique as it is well-suited to address complex issues where there is high divergence of opinion between different experts (Mukherjee et al., 2015). Compared to other qualitative techniques such as surveys, interviews or questionnaires, the Delphi technique is particularly useful in gathering consensus and exploring the rationale behind conflicting value positions (Mukherjee et al., 2018). This technique comprises two or more rounds of structured questionnaires, each followed by aggregation of responses and anonymous feedback to the participants (Mukherjee et al., 2015). Participants may reassess their views according to the feedback, which may also aid the reaching of a consensus (Lemieux and Scott, 2011). In our case, the Delphi technique consisted of three rounds, and respondents were invited to participate as authors in the final round after the analysis. The participants were unaware of each other's identity while the survey was being conducted. Ethics clearance was obtained from the University of Exeter before the survey was launched. Participation in the Delphi technique was based on informed consent and from the first round onwards, respondents were self-selected.

We selected a total of 55 European researchers recently active (i.e., $\geq 2$ publications in the last 10 years) in fields of WDH and wolf conservation through two complementary searches on the Scopus ${ }^{4}$ database. The searches were conducted on 28th February 2018 and the search terms used were ("wolf OR wolves+dog+hybrid* OR introgres*”) and ("wolf OR wolves+ecolog*+conserv"”), respectively. Two other experts were separately contacted based on a snowball sampling approach, which involves a non-random sampling method whereby respondents are asked to nominate other potential respondents (i.e., referrals; Vogt, 2005). The

${ }^{4}$ www.scopus.com
TABLE 2 | Total response rate to this survey, and response rate by expert title.

\begin{tabular}{lccc}
\hline Expert title & \multicolumn{3}{c}{ Delphi survey phase } \\
\cline { 2 - 4 } & Round I & Round II & Round III \\
\hline Ecologist & 22 & 17 & 17 \\
Geneticist & 18 & 17 & 17 \\
Biologist & 5 & 4 & 4 \\
Multidisciplinary scientist & 1 & 1 & 1 \\
Sustainability scientist & 1 & 1 & 1 \\
Ethologist & 1 & 1 & 1 \\
Eco-statistician & 1 & 1 & 1 \\
\hline Total & 49 & $86 \%$ & 42 \\
\hline Response rate & $86 \%$ & & $100 \%$ \\
\hline
\end{tabular}

experts self-identified themselves within their professional discipline (Table 2).

The questionnaire for Round I, comprised of fourteen questions, was structured and derived from the current management guidelines ${ }^{2,3}$ on WDH. Respondents were provided with the option to explain their responses in Round I and II. The questions for Round II $(n=30)$ were derived from a thematic analysis of the responses received in Round I. Item-specific (IS) responses were selected over agree/disagree responses, since they can significantly reduce the risk of response biases in social surveys (Saris et al., 2010; Höhne and Krebs, 2018). Finally, Round III was a structured, close-ended survey aimed at reaching a consensus on the issues that remained unresolved in Round II. One additional (open-ended) question was included in this round, to address in greater detail the definition and establishment of a genetic threshold to identify hybrids. None of the questions were compulsory, and the experts were made aware that all of their responses were anonymous with respect to the other participants. The questions of all the three rounds can be found in the Supplementary Material. The survey was performed via Google forms.

For the purpose of this study a clear distinction was drawn between three categories of free-ranging dogs (Boitani et al., 2006):

(a) Stray dogs are abandoned and survive on the streets or in the countryside, and are relatively comfortable around people as they were previously in contact with them;

(b) Feral dogs are born in the wild and were never in close contact with people, thus they might avoid humans or pose a threat to them;

(c) Owned free-ranging dogs have an owner but are left unguarded and are thus able to roam off their owner's property.

\section{Analysis}

Questions were organized along a gradient from conceptual to practical value (Figure 2). At the Ground Level and Level 1 (Figure 2) questions were targeted at the definition and management of admixed individuals. At higher levels (i.e., Levels 
2-4; Figure 2), questions were framed around management interventions to address WDH. We performed a permutational analysis of variance (PERMANOVA; Anderson, 2014) to test whether consensus significantly varied between question levels.

Using a percentage threshold to evaluate consensus is a widely-adopted approach in Delphi studies (Diamond et al., 2014). Setting the threshold depends strictly on context, and it is an arbitrary decision (Mukherjee et al., 2015). In a recent review of 98 consensus-based Delphi surveys, Diamond et al. (2014) report that the consensus threshold tends to range between 50 and $97 \%$, with $75 \%$ as the median value. Considering the inherent complexity of managing the anthropogenic hybridization issue, and the multifaceted factors possibly playing a role in fueling diverging opinions and debate in the scientific community (see Introduction), we decided to adopt a consensus threshold of $65 \%$ ( $\geq 27$ experts agreeing out of 42 ), just below the reported median value (Diamond et al., 2014). Crucially, the threshold value was decided before commencing the Delphi process (Mukherjee et al., 2015).

The reasons for dissensus amongst the experts were explored through a thematic analysis, which was performed using NVivo (Crotty, 1998). Through NVivo we were able to arrange the unstructured text collected through our survey into conceptual themes, following an inductive approach. Such thematic arrangement was key to neatly provide explanations for some of the findings of this study. When assessing consensus level (i.e., Round II and III), a KruskallWallis test was also performed to explore whether experts specialized in different subdisciplines held significantly different opinions. To this aim, only ecologists and geneticists were considered for this analysis, considering the small sample size of other groups.

\section{RESULTS}

Forty-two experts completed all three rounds of the Delphi (Table 2). Agreement was reached on 18 out of 30 questions, after three rounds of investigation. Consensus significantly varied between question levels (PERMANOVA, $p=0.05)$; as question levels increased, consensus decreased (Figure 3).

\section{Definition and Context}

Consensus was reached among experts that anthropogenic hybridization should always be mitigated (32/42 experts agreeing).

Experts (30/42) agreed on always defining admixed individuals according to their genetic profile. Experts (28/42) also agreed that management strategies should always be aimed at preserving the genetic integrity of the species, ensuring that evolutionary and ecological processes are maintained exempt from anthropogenic interference. Moreover, experts (33/42) agreed that admixed individuals should be managed by formal institutions only, rather than by hunters or the general public (Figure 4).

\section{Identification of Admixed Individuals}

Experts (27/42) agreed that a genetic threshold, representing a probability value beyond which an individual is considered to be a hybrid (such as the $q$-value in assignment tests; Pacheco et al., 2017) should always be used in detecting admixed individuals. Experts (27/42) also agreed that such a threshold should be established through simulation studies aimed to minimize the risk of incurring assignment errors (i.e., Type I and Type II errors). Moreover, experts (27/42) agreed that, in small wolf populations, Type II errors should be expected to have the most meaningful conservation consequences, and they should be preferentially avoided in such situations (Figure 4).

Experts (32/42) agreed that sometimes genome-wide analyses should be adopted for the purpose of management (Figure 4). Amongst the seven experts who provided an explanation for "sometimes," two suggested that whether or not to use genomewide analyses would depend upon the quality of the samples collected. Another two suggested adopting them only when circumstances are neither critical nor urgent, since these analyses could be highly time-consuming. Two more experts suggested that genome-wide analyses should be adopted for backcrossed individuals only, since they are the least conspicuous from a genetic perspective. Lastly, one expert suggested that genomewide analyses may be adopted in demographically threatened wolf populations which may be the most vulnerable to the effects of assignment errors (i.e., both Type I and II errors).

Experts did not agree on how to consider individuals bearing putative morphological traits indicating hybridization (e.g., Ciucci et al., 2003), but which are genetically identified as nonadmixed (Figure 4). Amongst the 13 experts who provided an explanation for their response, five suggested that anomalous phenotypic traits may not always be a reliable sign of admixture, and that diagnoses should always be based on genetic evidence. In contrast, the remaining experts suggested that the choice may vary according to technical circumstances, such as the laboratories that conducted the analyses and the respective number of genetic markers used.

Experts also did not agree on whether admixed individuals should be conserved if they are good ecological surrogates of parental individuals (Figure 4). Amongst the nine experts who provided an explanation to their response, three opposed, and two were skeptical, about adopting this approach because there is a paucity of data on whether admixed individuals can actually be considered good ecological surrogates of parental individuals. One expert also opposed this approach because admixed individuals may be poorly perceived by and have lower conservation value to the public regardless of their ecological role. In contrast, three experts were open to the idea of adopting this approach, because they valued the ecological role of admixed individuals regardless of their genetic identity.

Lastly, experts did not agree on whether admixed individuals should be conserved if they have greater evolutionary potential than parental individuals (e.g., increased Darwinian fitness; Figure 4). Amongst the nine experts who provided an explanation to their response, three opposed this approach because management should not be aimed at preserving fitter, 


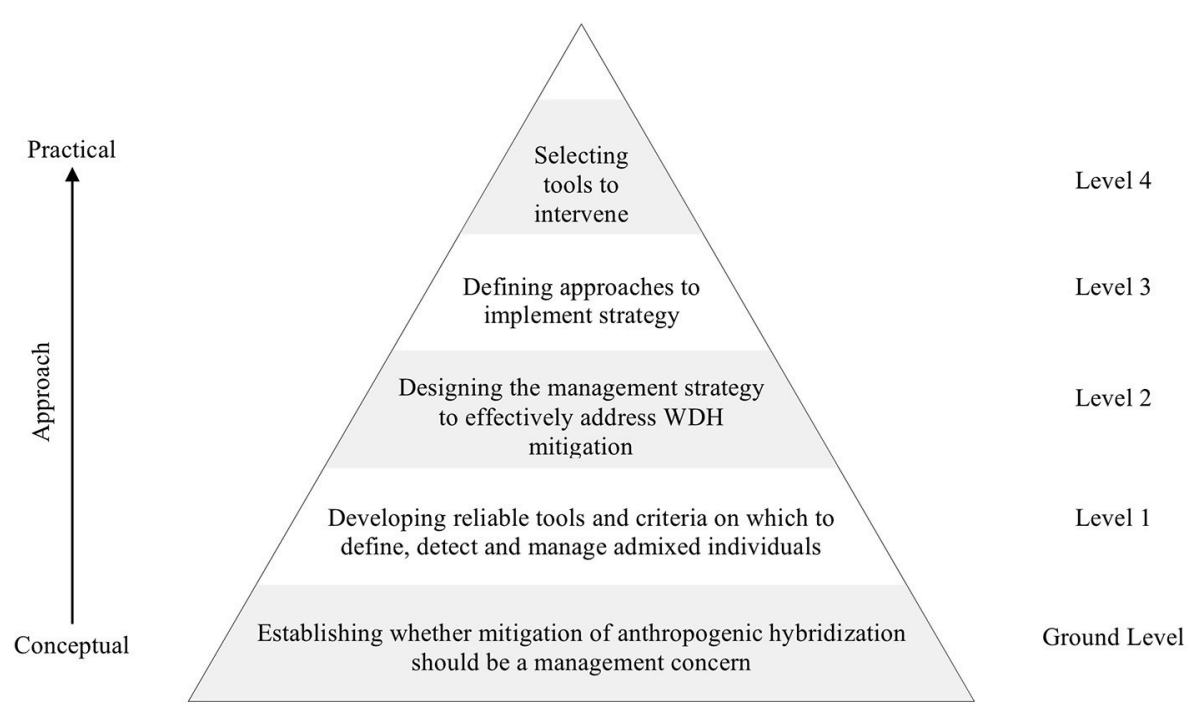

FIGURE 2 | Hierarchical structure of the questions used in a Delphi survey to assess the degree of consensus among 42 European experts in dealing with management of wolf $\times$ dog hybridization. The questions in this survey were ranked according to the type of approach they addressed, from conceptual to practical, aiming to investigate at which level disagreement occurred. At the Ground Level is found Q1. At Level 1 are found questions 2-11. At Level 2 are found questions 12-15. At Level 3 are found questions 16-26. At Level 4 are found questions 27-30. See Supplementary Materials for the questions.

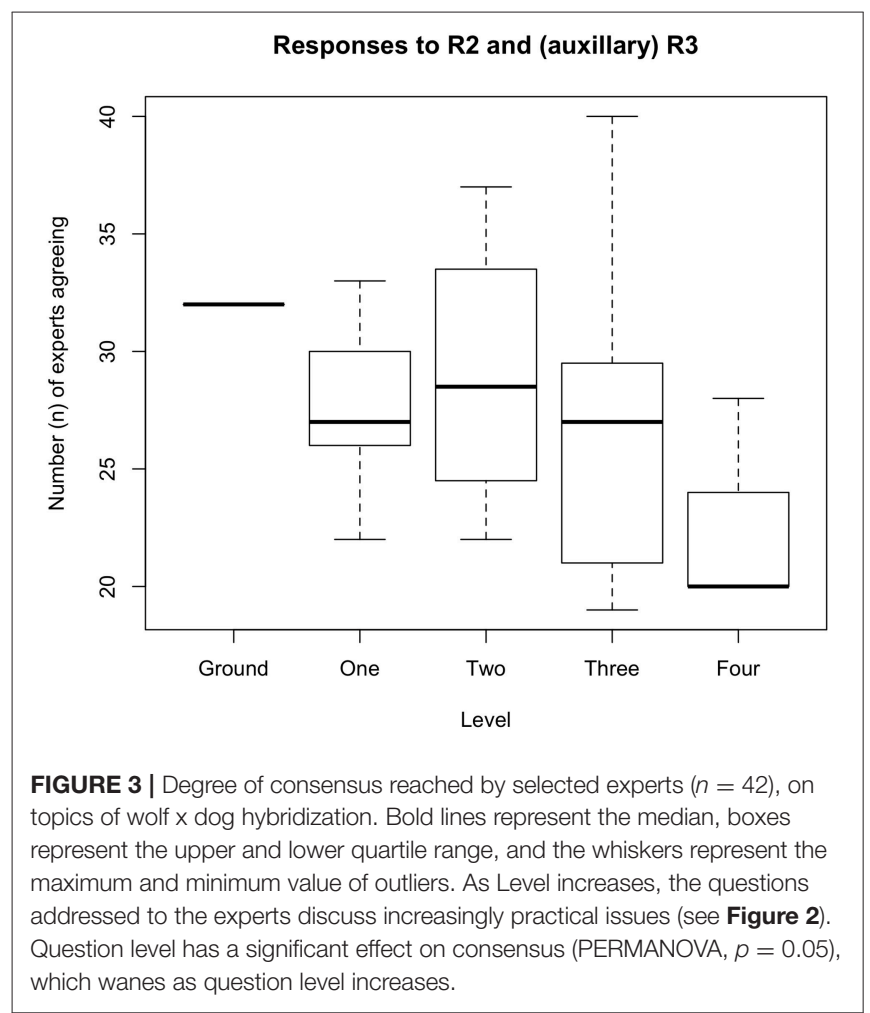

rather than preserving natural, populations. One expert was supportive of this approach because admixture may allow populations to adapt to changing environmental conditions. The remaining experts were skeptical about using this approach, because there is a lack of knowledge on whether, and what, traits may bring increased fitness to admixed individuals over the long-term.

\section{Management}

Experts agreed to always implement preventive (i.e., community education) and proactive (e.g., control of free-ranging dogs, constraining human-driven factors facilitating WDH) interventions (37/42 and 30/42 experts, respectively). In contrast, experts (27/42) agreed on using reactive interventions (i.e., the active management of admixed individuals) only for small and recovering wolf populations. The use of reactive interventions in large and stable populations did not reach consensus. Amongst the 20 experts who provided an explanation to their response, two suggested that active management should always be applied as much as possible to prevent gene introgression. In contrast, another two suggested that single admixed individuals do not pose a significant genetic threat to stable and large wild populations, and thus active management in these cases should not be adopted. The remaining experts suggested that such choices would depend on the spread and rate of hybridization in local contexts.

Experts (30/42) agreed that sometimes capture, sterilization and captivity may need to be adopted as a management intervention for admixed individuals (Figure 5). Amongst the eight experts who explained their response, all suggested that one such a circumstance favoring the use of captivity would be a social context in which lethal removal is strongly opposed by the public.

In contrast, experts did not agree on whether to adopt capture, sterilization and release (i.e., the placeholder concept; Gese and Terletzky, 2015) as a non-lethal measure (Figure 5). Dissensus was driven by diverging ethical and socio-ecological views. Amongst the 16 experts who provided an explanation to their 


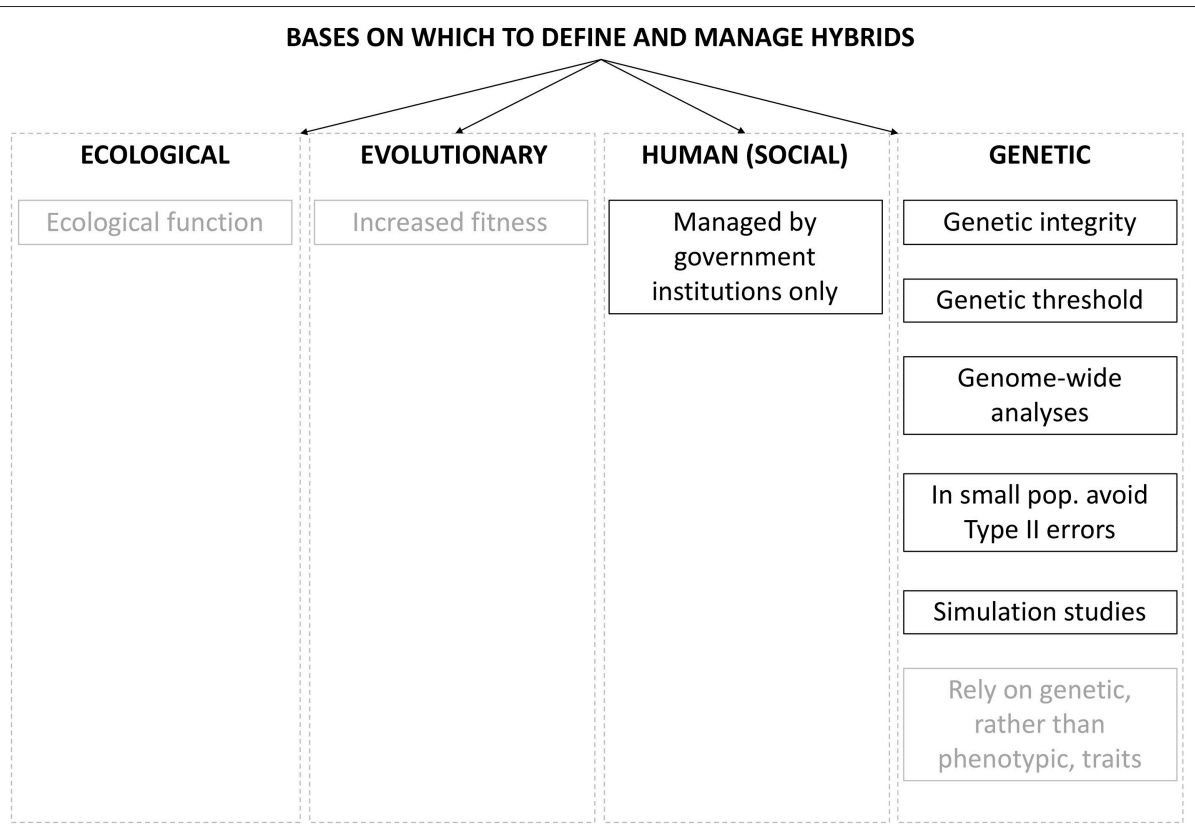

FIGURE 4 | Visual representation of conceptual areas of wolf $x$ dog hybridization where consensus was reached, in a Delphi study with a group of selected experts ( $n$ $=42$ ). Four dimensions/bases (i.e., Ecological, Evolutionary, Human, Genetic) are adopted to characterize definition issues, and their respective management implications (in the boxes underneath them). Boxes outlined in black reached consensus (i.e., at least 27/42 experts agreeing). Boxes faded-in did not reach consensus, and the respective topics they address need to be particularly emphasized in discussions and symposium settings, to aid effective management.

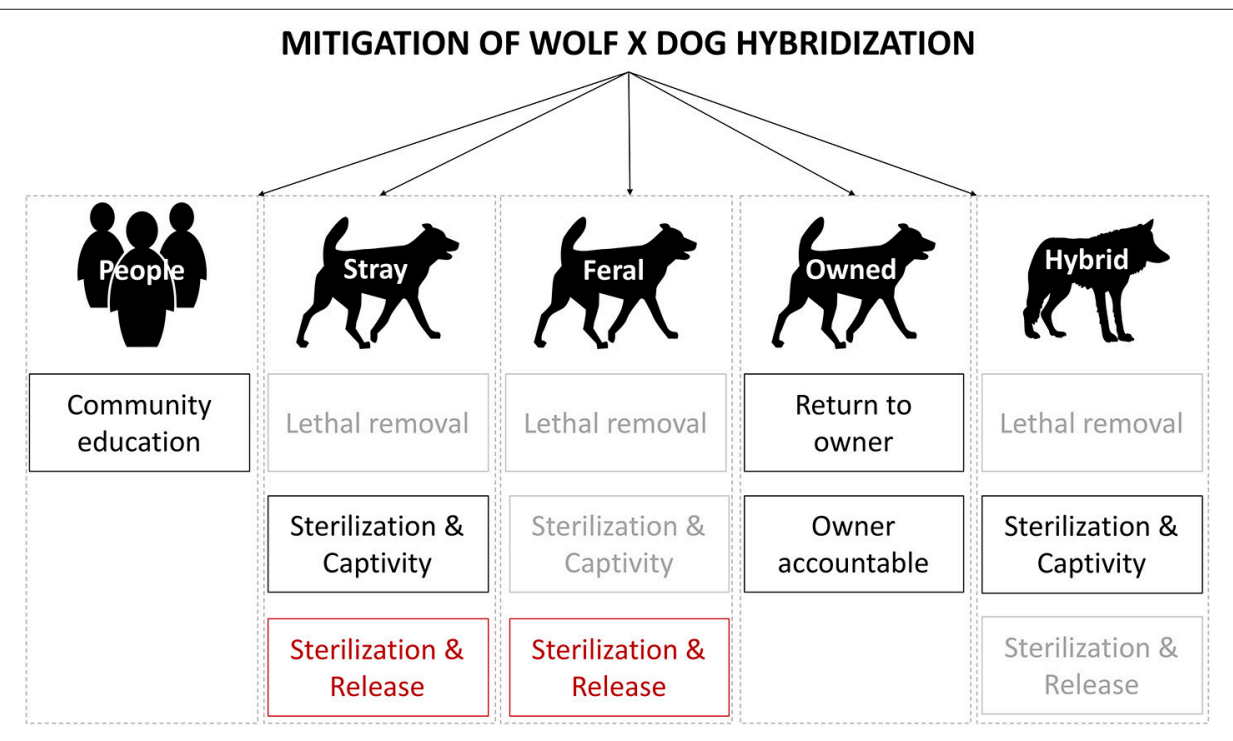

FIGURE 5 | Visual representation of management interventions to mitigate wolf $\times$ dog hybridization, explored in a Delphi study with a group of selected experts ( $n=42$ ). Management approaches on which experts' consensus (i.e., at least 27/42 experts agreeing) was reached are outlined in black. Consensus was reached against the management approaches that are outlined in red. Approaches that are faded-in did not reach consensus, and deserve particular emphasis in discussions and symposium settings, to aid effective management.

response, five suggested never releasing admixed individuals because of either: (i) increased resource competition with wolves, (ii) potential conflicts with livestock, or because (iii) the presence of admixed individuals in wolf populations may affect the social perception of the latter. The remaining experts suggested that whether or not release should be available as a tool would depend upon local contexts, such as the social attitudes toward the release of individuals. Nonetheless, should admixed individuals be captured, sterilized, and released, experts (28/42) agreed that sterilization should be performed through methods ensuring 
the maintenance of regular hormonal levels, associated with the normal social and territorial behavior of the individuals concerned (Figure 5).

Experts did not agree on whether to lethally remove admixed individuals (Figure 5), and in this case the dissensus was influenced by diverging ethical viewpoints. Amongst the 21 experts who provided an explanation to their response, four supported it on the basis of being the most humane method, and another five supported it because management needs access to a range of different tools. In contrast, three experts opposed lethal removal of admixed individuals because it would be morally wrong, and another expert opposed it because it would be socially unacceptable among the public. The remaining experts suggested adopting it only as a last resort, when no other interventions are feasible. None of the lethal tools for removal of admixed individuals (i.e., direct shooting, removal of pups from dens, and live-capture followed by euthanasia) reached the consensus threshold (Figure 5).

When managing stray and feral dogs, experts' consensus was reached against the use of capture, sterilization, and release (Figure 5), both times with 27/42 experts agreeing. This was largely due to the socio-ecological impacts of free-ranging dogs that extend beyond wolf conservation (e.g., predation on wild animals and livestock, involvement in zoonosis, and potential danger for people).

Experts (30/42) agreed that capture, sterilization, and captivity should always be available as a management intervention for stray dogs. Experts also agreed that owned, but free-ranging dogs should always be captured and returned to their owner, and that their owners should always be considered accountable by local law for letting their dogs loose (29/42 and 40/42 experts, respectively). No consensus was reached on adopting lethal means to manage free-ranging dogs (Figure 5). Amongst the experts who explained their response, two opposed lethal removal of both stray and feral dogs because this tool would be either socially unacceptable, or morally wrong. In contrast, two experts who supported lethal removal considered it an efficient and practical tool. Lastly, six experts considered adopting lethal removal only occasionally, such as when dogs cause issues with people, or when there is no feasible alternative.

Experts from different disciplines gave significantly different responses to five questions in the consensus-based rounds of the survey (i.e., Round II and III). Overall, ecologists were more supportive of reactive interventions and lethal removal than geneticists (Figure 6). For instance, 10/17 ecologists compared to $4 / 17$ geneticists supported a systematic removal of admixed individuals from stable wolf populations (Kruskas-Wallis Test, $p=0.03$; Figure 6).

\section{Differences Between Rounds}

Although not all the questions reached consensus after Round III, consensus levels increased from Round II to III, on three questions. Disagreement decreased concerning the adoption of reactive interventions in large and stable wolf populations (from 12/42 experts replying "never," to 3/42), while agreement increased (from 9/17 experts replying “always," to 17/42). Disagreement also decreased toward the lethal removal of stray dogs (from 10/42 experts replying "never," to 6/42), while agreement increased (from 9/17 experts replying "always," to 13/42). Lastly, disagreement decreased toward the lethal removal of wolf pups from dens (from 12/42 experts replying "never," to $7 / 42$ ).

\section{DISCUSSION}

Despite disagreement on some WDH issues, the experts agreed that anthropogenic hybridization represents a conservation problem that needs to be mitigated. Such agreement provides bases for further development in the debate amongst scientists. Furthermore, it allows us to conclude, through our survey, that there is agreement at the level of the problem but not quite yet at the level of the solutions (i.e., mitigation strategies).

Although not all experts were geneticists, agreement was reached on the need for a genetic-based evidence to detect admixed individuals (Figure 4). In particular, the experts agreed on using a probabilistic threshold based on simulation studies and, when managing small and recovering wolf populations, on always showing a preference toward adopting a conservative threshold-that is, toward a relatively lower risk of incurring Type II error. Agreement on the need to base management interventions on genetic assessments suggests that the standards currently reached by genetic tools (e.g., type and number of markers, diagnostic procedures; cf., Hindrikson et al., 2017) provide more coherent and objective results compared to those obtainable using phenotypic cues. On this note, consensus on how to define hybrids provides concrete indications to establish legal framework, normative, and management criteria/protocols.

Experts' agreement tended to be stronger at lower, more conceptual levels, and weaker at higher, more practical levels of the WDH conceptual framework (Figure 3). In particular, while the use of preventive, proactive, and reactive interventions (especially in small and recovering wolf populations) reached consensus, lack of agreement prevailed on the tools to implement reactive interventions, especially concerning the adoption of lethal removal (Figure 5). Firstly, this finding suggests that possible value-laden viewpoints held by scientists of different expertise and disciplinary backgrounds increasingly emerge when dealing with practical, hands-on issues. Although we cannot dismiss the role that other confounding factors (e.g., age, gender, cultural background, country of origin, working context, perception of management issues) may play in affecting experts' opinions, we believe that the contrast between, and the commonalities within, disciplines that we observed reveal the overarching effect that the educational background and the field of expertise may have in shaping experts' points of view. This hints to an ongoing "paradigm shift" (i.e., the shift of intellectual frameworks of ideas; Kuhn, 1962) in conservation biology, whereby communities of scientists, each specialized in their own field, progressively develop intrinsically contrasting views on how to handle wildlife management problems. Embracing the idea of shifting paradigms is central to avoid alienating parts of the scientific community, and to promote a more unified scientific knowledge and wisdom, which is pivotal to effectively transmit a 
Responses of Ecologists and Geneticists to the Delphi survey

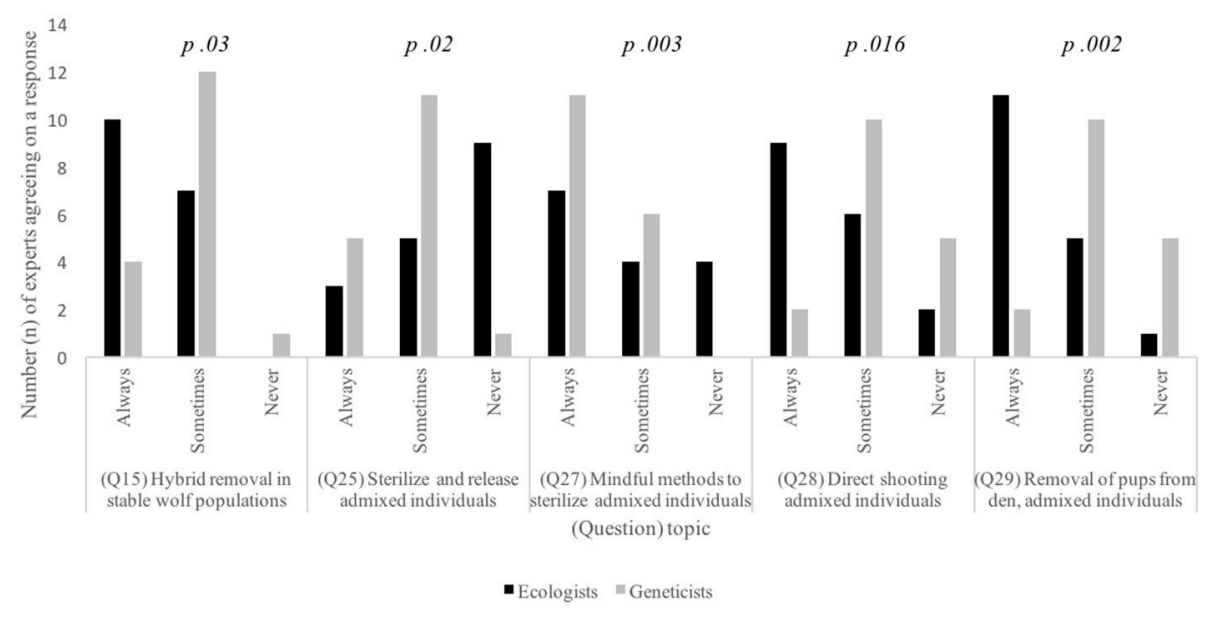

FIGURE 6 | Responses to a series of questions on wolf $\mathrm{x}$ dog hybridization by a selected group of experts, who self-identified themselves as either ecologists ( $n=17$ ) or geneticists $(n=17)$. The $p$-value in italics indicates that the responses of ecologists and geneticists were significantly different (Kruskal-Wallis Test). Ecologists were more supportive of reactive interventions and lethal removal than geneticists.

conservation concern to the society at large (Lewandowsky et al., 2013; Aklin and Urpelainen, 2014).

Secondly, opposition toward lethal removal of admixed individuals may arise as a form of strategic conservation planning amongst the respondents in our study. Some scientists may prefer avoiding the risk of giving carte blanche to wolf opponents to (illegally) remove wolves based on the WDH issue, as it is already occurring in parts of Europe (e.g., Peltola and Heikkilä, 2018). While this point was not specifically raised by the respondents to the appropriate question (i.e., lethal removal), it explains the strong consensus reached on the management of admixed individuals by formal institutions only, as opposed to by hunters or the general public. Moreover, this point was also raised by the respondents when discussing the implementation of reactive interventions.

Thirdly, disagreement and the influence of value-laden viewpoints on the scientific debate underline the lack of scientific evidence on the effectiveness of management alternatives (e.g., lethal removal vs. sterilization and release). Controversial management tools for $\mathrm{WDH}$ are currently proposed in the absence of clear evidence from scientific studies. While this is customary in conservation biology as a crisis discipline (Walters and Hilborn, 1978; Burgman, 2005), when the recommended interventions touch upon issues that are particularly ethically and socially sensitive it is not surprising to face skepticism, disagreement, and lack of support (cf., van Eeden et al., 2017).

Rather than being a cultural taboo that evades the scientific rationale within the scientific community, these aspects should be urgently addressed by specific studies aimed at producing the necessary evidence to foster the scientific debate and consensus toward more robust, effective, and feasible management approaches. Approaches that are supported by scientific evidence may attract less controversy both within the scientific community and the society at large, even when they are socially and ethically challenging (Carter and Wiles, 2014). Contrastingly, controversial interventions may have expectedly lower chances of being agreed upon, and routinely adopted by management authorities, if they are not evidence-based.

Similar conclusions, concerning the dearth of studies, may be drawn about the lack of agreement documented on whether the ecological role and evolutionary potential of admixed individuals should influence management decisions (e.g., Daniels and Corbett, 2003; Fitzpatrick et al., 2015). In this context, hybridization between wild and farm salmon (Salmo salar) represents a textbook example of what scientific research can achieve when enough effort is undertaken. For instance, compared to wild salmon, F1 and B1 hybrids are poorer competitors (Skaala et al., 2012), grow significantly larger, and mature significantly slower (Yates et al., 2015). Nevertheless, further backcrosses seem to reach reproductive maturity earlier and gain higher breeding success than parental individuals, enhancing chances for gene introgression (Garant et al., 2003).

Through our survey, we observed that the recent literature on WDH is essentially represented by genetically-based studies compared to other disciplines relevant to management (e.g., ecology, behavioral ecology, physiology). This is foreseeable in a period when genetic tools/techniques are developing rapidly and are critically needed to provide answers to most fundamental issues (e.g., how to detect hybrids in a wild population), and without which any management progress would be either controversial or ineffective at best. However, this may also conceal an underlying issue if the views of experts of different background are significantly diverging. To that account, ecologists and wildlife managers are now in the position to build on the most recent developments in the field of genetics and conduct empirical, experimental, or simulation studies to design, inform, and support management programs through robust and reliable evidence. 


\section{Concluding Remarks}

The findings of our study on WDH can be applied to the broader issue of anthropogenic hybridization, given the current unresolved policies (e.g., Trouwborst, 2014; Piett et al., 2015; Wayne and Shaffer, 2016) and the likely hindered implementation of mitigation interventions (e.g., Salvatori and Ciucci, 2018). In a recent study, Lute et al. (2018) explored professionals' (including social and natural science researchers, wildlife managers and NGOs) views on large carnivore conservation, noting that greatest polarization of opinions occurred on the use of lethal removal. Our study corroborates Lute et al. (2018)'s findings, reinforcing the idea that dissensus on lethal removal represents a clear and tangible issue within the scientific community. In addition to ethical reasons, however, opposition to lethal removal as a WDH management tool by a large sector of the scientific community could also reflect awareness by scientists that this, on practical grounds, may provide wolf opponents with opportunities to remove wolves even when the act is illegal (e.g., Peltola and Heikkilä, 2018). Moreover, a paucity of experimental data on the effectiveness of lethal removal as a management intervention fosters the dissensus. Thereby, there is a need for empirical studies to advance an effective and evidence-based management of WDH.

Our study also provides a conceptual framework highlighting areas of scientific agreement/disagreement on topics of WDH, and anthropogenic hybridization in general, which may be a valuable tool in shaping focused debates (Figures 4, 5). Most crucially, we believe that such debates may benefit from (i) a clearer identification of the management goals and objectives (e.g., biological vs. political and socio-economic) and their temporal framework (i.e., short vs. long-term); and by (ii) obtaining empirical and reliable evidence on the effectiveness and feasibility of lethal removal as a management tool compared to available alternatives.

Dissensus within the scientific community can have far reaching consequences. In contexts of $\mathrm{WDH}$, one-size-fitsall solutions may not be feasible, and greater engagement in determining case-by-case interventions is recommended, especially within the scientific community, but also amongst scientists, practitioners and decision-makers.

\section{ETHICS STATEMENT}

This study was carried out in accordance with the recommendations of the University of Exeter Ethics Frameworks, with informed consent from all subjects, in accordance with

\section{REFERENCES}

Aklin, M., and Urpelainen, J. (2014). Perceptions of scientific dissent undermine public support for environmental policy. Environ. Sci. Policy 38, 173-177. doi: 10.1016/J.ENVSCI.2013.10.006

Allendorf, F. W., Leary, R. F., Spruell, P., and Wenburg, J. K. (2001). The problems with hybrids: setting conservation guidelines. Trends Ecol. Evol. 16, 613-622. doi: 10.1016/S0169-5347(01) 02290-X the Declaration of Helsinki. The protocol was approved by the University of Exeter Ethics Committee.

\section{AUTHOR CONTRIBUTIONS}

PC, VD, NM, and DB drafted the idea and designed the study. NM and PC assisted in the design of the Delphi rounds. VD and NM performed data collection and analysis. VD, NM, and PC wrote the manuscript. PC and VS assisted in selecting and contacting the experts. LA, EB, JB, LB, RC, AC, CC, GC, SC, EF, MG, AG, OG, RG, CG, MH, DH, PH, WJ, JK, JL-B, JL, LL, JB, PeM, FM, LM, PiM, CM, RM, AO, VP, HP, CP, MP, ER, AR, US, HS, MS, AS, and ET participated in the Delphi technique, contributed with intellectual input, and commented on a draft of the manuscript.

\section{ACKNOWLEDGMENTS}

We are grateful to experts: H. Andren, M. Apollonio, E. J. G. Fernandez, O. Liberg, S. Nowak, C. Vilà, and P. Wabakken who participated partially in this Delphi survey and contributed their time. We are grateful to Elleanor Gurr from the Royal Veterinary College (RVC) for her help in providing ideas and shaping discussions on anthropogenic hybridization. The following funding bodies are thanked by the respective authors: GC: Formas; OG: CNRS Mission pour l'Interdisciplinarité through its program Osez l'Interdisciplinarité; RG: Portuguese Foundation for Science and Technology (IF/00564/2012); MH: post-doctoral research grant from Estonian Research Council; CP: Aalborg Zoo Conservation Foundation (AZCF: grant number 3 and 4, 2018); MP: The Leverhulme Trust Research Fellowship (RF2017-185); US: Institutional research funding (IUT20-32) from the Estonian Ministry of Education and Research; JL: Research Council of Norway (grant 251112); AS: senior postdoctoral fellowship from Insubria University in Varese, Italy; JB: Ramon \& Cajal research contract (RYC-2015-18932) from the Spanish Ministry of Economy, Industry and Competitiveness; NM: NERC Grant/Award Number: NE/R006946/1 and Scriven fellowship. This work was supported by the Natural Environment Research Council [grant number NE/R006946/1].

\section{SUPPLEMENTARY MATERIAL}

The Supplementary Material for this article can be found online at: https://www.frontiersin.org/articles/10.3389/fevo. 2019.00175/full\#supplementary-material
Anderson, M. J. (2014). Permutational multivariate analysis of variance (PERMANOVA). Wiley Stats. Ref. 2014, 1-15. doi: $10.1002 / 9781118445112 . s t a t 07841$

Boitani, L. (2003). "Wolf conservation and recovery," in Wolves: Behavior, Ecology and Conservation, eds L. D. Mech and L. Boitani (Chicago:University of Chicago Press), 317-340.

Boitani, L., Ciucci, P., and Ortolani, A. (2006). "Behaviour and social ecology of free-ranging dogs," in The Behavioural Biology of Dogs, ed P. Jensen (Wallingford: CABI), 147-165. doi: 10.1079/9781845931872.0147 
Brennan, A. C., Woodward, G., Seehausen, O., Muñoz-Fuentes, V., Moritz, C., Guelmami, A., et al. (2014). Hybridization due to changing species distributions: adding problems or solutions to conservation of biodiversity during global change? Evol. Ecol. Res. 16, 475-491. doi: 10.1098/rsbl.2015.0303

Burgman, M. (2005). Risks and Decisions for Conservation and Environmental Management. Cambridge: Cambridge University Press. doi: 10.1017/CBO9780511614279

Caniglia, R., Fabbri, E., Greco, C., Galaverni, M., Manghi, L., Boitani, L., et al. (2013). Black coats in an admixed wolf $\times$ dog pack is melanism an indicator of hybridization in wolves? Eur. J. Wildl. Res. 59, 543-555. doi: 10.1007/s10344-013-0703-1

Carter, B. E., and Wiles, J. R. (2014). Scientific consensus and social controversy: exploring relationships between students' conceptions of the nature of science, biological evolution, and global climate change. Evol. Educ. Outreach 7:6. doi: 10.1186/s12052-014-0006-3

Ciucci, P., Lucchini, V., Boitani, L., and Randi, E. (2003). Dewclaws in wolves as evidence of admixed ancestry with dogs. Can. J. Zool. 81, 2077-2081. doi: $10.1139 / \mathrm{z} 03-183$

Crotty, M. (1998). The Foundations of Social Research: Meaning and Perspective in the Research Process. Thousand Oaks: Sage.

Daniels, M. J., and Corbett, L. (2003). Redefining introgressed protected mammals: when is a wildcat a wild cat and a dingo a wild dog? Wildl. Res. 30, 213-218. doi: 10.1071/WR02045

de Kerckhove, D. T., Rennie, M. D., and Cormier, R. (2015). Censoring government scientists and the role of consensus in science advice: a structured process for scientific advice in governments and peer-review in academia should shape science communication strategies. EMBO Rep. 16, 263-266. doi: $10.15252 / \mathrm{embr} .201439680$

Diamond, I. R., Grant, R. C., Feldman, B. M., Pencharz, P. B., Ling, S. C., et al. (2014). Defining consensus: a systematic review recommends methodologic criteria for reporting of Delphi studies. J. Clin. Epidemiol. 67, 401-409. doi: 10.1016/j.jclinepi.2013.12.002

Elledge, A. E., Allen, L. R., Carlsson, B. L., Wilton, A. N., and Leung, L. K. P. (2008). An evaluation of genetic analyses, skull morphology and visual appearance for assessing dingo purity: implications for dingo conservation. Wildl. Res. 35, 812-820 doi: 10.1071/WR07056

Fan, Z., Silva, P., Gronau, I., Wang, S., Armero, A. S., Schweizer, R. M., et al. (2016). Worldwide patterns of genomic variation and admixture in gray wolves. Genome Res. 26, 163-173. doi: 10.1101/gr.197517.115

Fitzpatrick, B. M., Ryan, M. E., Johnson, J. R., Corush, J., and Carter, E. T. (2015). Hybridization and the species problem in conservation. Curr. Zool. 61, 206-216. doi: 10.1093/czoolo/61.1.206

Fix, P. J., Teel, T. L., Manfredo, M. J., and Boston, S. S. (2010). Assessing public acceptance of wildlife management trade-offs: a case study of elk and vegetation management in Rocky Mountain National Park, Colorado. Hum. Dimens. Wildl. 15, 405-417. doi: 10.1080/10871209.2010.503235

Freedman, A. H., Gronau, I., Schweizer, R. M., Ortega-Del Vecchyo, D., Han, E., Silva, P. M., et al. (2014). Genome sequencing highlights the dynamic early history of dogs. PLoS Genet. 10:e1004016. doi: 10.1371/journal.pgen.1004016

Galaverni, M., Caniglia, R., Pagani, L., Fabbri, E., Boattini, A., and Randi, E. (2017). Disentangling timing of admixture, patterns of introgression, and phenotypic indicators in a hybridizing wolf population. Mol. Biol. Evol. 34, 2324-2339. doi: 10.1093/molbev/msx169

Garant, D., Fleming, I. A., Einum, S., and Bernatchez, L. (2003). Alternative male life-history tactics as potential vehicles for speeding introgression of farm salmon traits into wild populations. Ecol. Lett. 6, 541-549. doi: 10.1046/j.1461-0248.2003.00462.x

Gese, E. M., Knowlton, F. F., Adams, J. R., Beck, K., Fuller, T. K., Murray, D. L., et al. (2015). Managing hybridization of a recovering endangered species: the red wolf Canis rufus as a case study. Curr. Zool. 61, 191-205. doi: 10.1093/czoolo/61.1.191

Gese, E. M., and Terletzky, P. A. (2015). Using the 'placeholder' concept to reduce genetic introgression of an endangered carnivore. Biol. Conserv. 192, 11-19. doi: 10.1016/j.biocon.2015.09.003

Glen, A. S. (2010). Hybridisation between dingoes and domestic dogs: a comment on Jones (2009). Aust. Mammal. 32, 76-77. doi: 10.1071/AM09031

Godinho, R., Llaneza, L., Blanco, J. C., Lopes, S., and Álvares, F., García, E. J., et al. (2011). Genetic evidence for multiple events of hybridization between wolves and domestic dogs in the Iberian Peninsula. Mol. Ecol. 20, 5154-5166. doi: 10.1111/j.1365-294X.2011.05345.x

Godinho, R., López-Bao, J. V., Castro, D., Llaneza, L., Lopes, S., Silva, P., et al. (2015). Real-time assessment of hybridization between wolves and dogs: combining noninvasive samples with ancestry informative markers. Mol. Ecol. Resour. 15, 317-328. doi: 10.1111/1755-0998.12313

Gompert, Z., and Buerkle, C. A. (2016). What, if anything, are hybrids: enduring truths and challenges associated with population structure and gene flow. Evol. Appl. 9, 909-923. doi: 10.1111/eva.12380

Gottelli, D., Sillero-Zubir,1, C., Applebaum, G. D., Roy, S. M. S., and Girman, D. J., Garcia-Moreno, S. J., et al. (1994). Molecular genetics of the most endangered canid: the Ethiopian wolf Canis simensis. Mol. Ecol. 3, 301-312. doi: 10.1111/j.1365-294X.1994.tb00070.x

Hindrikson, M., Männil, P., Ozolins, J., Krzywinski, A., and Saarma, U. (2012) Bucking the Trend in wolf-dog hybridization: first evidence from Europe of hybridization between female dogs and male wolves. PLOS ONE 7:e46465. doi: 10.1371/journal.pone.0046465

Hindrikson, M., Remm, J., Pilot, M., Godinho, R., Stronen, A. V., Baltrunait,é, L., et al. (2017). Wolf population genetics in Europe: a systematic review, meta-analysis and suggestions for conservation and management. Biol. Rev. 92, 1601-1629. doi: 10.1111/brv.12298

Höhne, J. K., and Krebs, D. (2018). Scale direction effects in agree/disagree and item-specific questions: a comparison of question formats. Int. J. Soc. Res. Methodol. 21, 91-103. doi: 10.1080/13645579.2017.1325566

Jackiw, R. N., Mandil, G., and Hager, H. A. (2015). A framework to guide the conservation of species hybrids based on ethical and ecological considerations. Conserv. Biol. 29, 1040-1051. doi: 10.1111/cobi.12526

Khosravi, R., Rezaei, H. R., and Kaboli, M. (2013). Detecting Hybridization between Iranian wild wolf (Canis Lupus Pallipes) and free-ranging domestic $\operatorname{dog}$ (Canis Familiaris) by analysis of microsatellite markers. Zoolog. Sci. 30, 27-34. doi: 10.2108/zsj.30.27

Kuhn, T. (1962). The structure of scientific revolutions. Chicago: Chicago University Press

Kusak, J., Fabbri, E., Galov, A., Gomerčić, T., Arbanasić, H., Caniglia, R., et al. (2018). Wolf-dog hybridization in Croatia. Vet. Arh. 88, 375-395. doi: 10.24099/vet.arhiv.170314

Lavrenchenko, L. A., and Bulatova, N. S. (2016). The role of hybrid zones in speciation: a case study on chromosome races of the house mouse Mus domesticus and common shrew Sorex araneus. Biol. Bull. Rev. 6, 232-244. doi: 10.1134/S2079086416030051

Lemieux, C. J., and Scott, D. J. (2011). Changing climate, challenging choices: identifying and evaluating climate change adaptation options for protected areas management in Ontario, Canada. Environ. Manage. 48, 675-690. doi: 10.1007/s00267-011-9700-x

Leonard, J. A., Echegaray, J., Rand, E., and Vilà, C. (2014). "Impact of hybridization with domestic dogs on the conservation of wild canids," in Free-Ranging Dogs and Wildlife Conservation, ed M. E Gompper (Oxford: Oxford University Press), 170-184. doi: 10.1093/acprof:osobl/9780199663217.003.0007

Lescureux, N. (2018). "Beyond wild and domestic: human complex relationships with dogs, wolves, and wolf-dog hybrids," in Hybrid Communities, eds C. Stépanoff and J. D. Vigne (London: Routledge), 83-98.

Lewandowsky, S., Gignac, G. E., and Vaughan, S. (2013). The pivotal role of perceived scientific consensus in acceptance of science. Nat. Clim. Chang. 3, 399-404. doi: 10.1038/nclimate1720

Lewis, P.-M., Burns, G. L., and Jones, D. (2017). Response and responsibility: humans as apex predators and ethical actors in a changing societal environment. Food Webs 12, 49-55. doi: 10.1016/J.FOOWEB.2016.09.001

Lorenzini, R., Fanelli, R., Grifoni, G., Scholl, F., and Fico, R. (2014). Wolf-dog crossbreeding: 'Smelling' a hybrid may not be easy. Mamm. Biol. 79, 149-156. doi: 10.1016/j.mambio.2013.07.080

Lute, M. L., Carter, N. H., López-Bao, J. V., and Linnell, J. D. C. (2018). Conservation professionals agree on challenges to coexisting with large carnivores but not on solutions. Biol. Conserv. 218, 223-232. doi: 10.1016/j.biocon.2017.12.035

Manfredo, M. J., Teel, T. L., and Bright, A. D. (2003). Why are public values toward wildlife changing? Hum. Dimens. Wildl. 8, 287-306. doi: 10.1080/716100425

Mukherjee, N., Hugé, J., Sutherland, W. J., McNeill, J., Van Opstal, M., DahdouhGuebas, F., et al. (2015). The Delphi technique in ecology and biological 
conservation: applications and guidelines. Methods Ecol. Evol. 6, 1097-1109. doi: 10.1111/2041-210X.12387

Mukherjee, N., Zabala, A., Huge, J., Nyumba, T. O., Adem Esmail, B., and Sutherland, W. J. (2018). Comparison of techniques for eliciting views and judgements in decision-making. Methods Ecol. Evol. 9, 54-63. doi: 10.1111/2041-210X.12940

Nelson, M. P., Bruskotter, J. T., Vucetich, J. A., and Chapron, G. (2016). Emotions and the ethics of consequence in conservation decisions: lessons from Cecil the Lion. Conserv. Lett. 9, 302-306. doi: 10.1111/conl.12232

Pacheco, C., López-Bao, J. V., García, E. J., Lema, F. J., Llaneza, L., Palacios, V., et al. (2017). Spatial assessment of wolf-dog hybridization in a single breeding period. Sci. Rep. 7:42475. doi: 10.1038/srep42475

Peltola, T., and Heikkilä, J. (2018). Outlaws or protected? DNA, hybrids, and biopolitics in a finnish wolf-poaching case. Soc. Anim. 26, 197-216. doi: 10.1163/15685306-12341509

Piett, S., Hager, H. A., and Gerrard, C. (2015). Characteristics for evaluating the conservation value of species hybrids. Biodivers. Conserv. 24, 1931-1955. doi: 10.1007/s10531-015-0919-3

Pilot, M., Greco, C., vonHoldt, B. M., Randi, E., Jedrzejewski, W., Sidorovich, V. E., et al. (2018). Widespread, long-term admixture between grey wolves and domestic dogs across Eurasia and its implications for the conservation status of hybrids. Evol. Appl. 11, 662-680. doi: 10.1111/eva.12595

Randi, E. (2008). Detecting hybridization between wild species and their domesticated relatives. Mol. Ecol. 17, 285-293. doi: 10.1111/j.1365-294X.2007.03417.x

Randi, E. (2011). Genetics and conservation of wolves Canis lupus in Europe. Mamm. Rev. 41, 99-111. doi: 10.1111/j.1365-2907.2010.00176.x

Randi, E., Hulva, P., Fabbri, E., Galaverni, M., Galov, A., Kusak, J., et al. (2014). Multilocus detection of wolf $\mathrm{x}$ dog hybridization in italy, and guidelines for marker selection. PLoS ONE. 9:e86409. doi: 10.1371/journal.pone.0086409

Rhymer, J. M., and Simberloff, D. (1996). Extinction by hybridization and introgression. Annu. Rev. Ecol. Evol. Syst. 27, 83-109. doi: 10.1146/annurev.ecolsys.27.1.83

Rohwer, Y., and Marris, E. (2015). Is there a prima facie duty to preserve genetic integrity in conservation biology? Ethics Policy Environ. 18, 233-247. doi: 10.1080/21550085.2015.1111629

Salvatori, V., and Ciucci, P. (2018). "Wolf-dog hybridization: issues on detection and management across Europe," in Wolf-human coexistence in the Alps and in Europe. Abstract retrieved from Abstract Book of the International Final Conference of the LIFE WOLFALPS project, 19-20 March 2018, eds F. Marucco, C. Maiolini, M. Gandolfi, and L. Boitani (Trento) p. 67.

Saris, W. E., Revilla, M., Krosnick, J. A., and Shaeffer, E. M. (2010). Comparing questions with agree/disagree response options to questions with item-specific response options. Survey Res. Methods 4, 61-79. doi: 10.18148/srm/2010.v4i1.2682

Skaala, Ø., Glover, K. A., Barlaup, B. T., Svåsand, T., Besnier, F., Hansen, M. M., et al. (2012). Performance of farmed, hybrid, and wild Atlantic salmon (Salmo salar) families in a natural river environment. Can. J. Fish. Aquat. Sci. 69, 1994-2006. doi: 10.1139/f2012-118

Teel, T. L., and Manfredo, M. J. (2010). Understanding the diversity of public interests in wildlife conservation. Conserv. Biol. 24,128-139. doi: $10.1111 / j .1523-1739.2009 .01374 . x$

Trouwborst, A. (2014). Exploring the legal status of Wolf-dog hybrids and other dubious animals: International and EU law and the wildlife conservation problem of hybridization with domestic and alien species. Rev. Eur. Comp. Int. Environ. Law 23, 111-124. doi: 10.1111/reel.12052

US Fish and Wildlife Service (1996). Endangered and threatened wildlife and plants; proposed policy and proposed rule on the treatment of intercrosses and intercross progeny (the issue of 'hybridization'); Request for public comment. Federal Register. 61, 4710-4713

van der Linden, S. L., Leiserowitz, A. A., Feinberg, G. D., and Maibach, E. W. (2015). The scientific consensus on climate change as a gateway belief: experimental evidence. PLoS ONE 10:e0118489. doi: 10.1371/journal.pone.0118489

van Eeden, L. M., Dickman, C. R., Newsome, T. M., and Crowther, M. S. (2018). What should we do with wild dogs? Taxonomic tangles and the management of dingo-dog hybridisation. Aust. Zool. doi: 10.7882/AZ. 2018.031. [Epub ahead of print].

van Eeden, L. M., Dickman, C. R., Ritchie, E. G., and Newsome, T. M. (2017). Shifting public values and what they mean for increasing democracy in wildlife management decisions. Biodivers. Conserv. 26, 2759-2763. doi: 10.1007/s10531-017-1378-9

Vilà, C., Walker, C., Sundqvist, A.-K., Flagstad, Ø., Andersone, Z., Casulli, A., et al. (2003). Combined use of maternal, paternal and bi-parental genetic markers for the identification of wolf-dog hybrids. Heredity 90, 17-24. doi: $10.1038 /$ sj.hdy. 6800175

Vogt, W. P. (2005). Dictionary of Statistics and Methodology: A Nontechnical Guide for the Social Sciences. London:Sage.

von Essen, E., and Allen, M. P. (2016). A Rabble in the Zoopolis? Considering Responsibilities for Wildlife Hybrids. J. Soc. Philos. 47, 171-187. doi: 10.1111/josp.12150

vonHoldt, B. M., Kays, R., Pollinger, J. P., and Wayne, R. K. (2016). Admixture mapping identifies introgressed genomic regions in North American canids. Mol. Ecol. 25, 2443-2453. doi: 10.1111/mec.13667

VonHoldt, B. M., Pollinger, J. P., Earl, D. A., Knowles, J. C., Boyko, A. R., Parker, H., et al. (2011). A genome-wide perspective on the evolutionary history of enigmatic wolf-like canids. Genome Res. 21, 1294-1305. doi: $10.1101 /$ gr.116301.110

Wallach, A. D., Bekoff, M., Nelson, M. P., and Ramp, D. (2015). Promoting predators and compassionate conservation. Conserv. Biol. 29, 1481-1484. doi: $10.1111 /$ cobi. 12525

Walters, C. J., and Hilborn, R. (1978). Ecological optimization and adaptive management. Annu. Rev. Ecol. Syst. 9, 157-188. doi: 10.1146/annurev.es.09.110178.001105

Way, J. G., and Bruskotter, J. T. (2012). Additional considerations for gray wolf management after their removal from Endangered Species Act protections. J. Wildl. Manage. 76, 457-461. doi: 10.1002/jwmg.262

Wayne, R. K., and Shaffer, H. B. (2016). Hybridization and endangered species protection in the molecular era. Mol. Ecol. 25, 2680-2689. doi: $10.1111 / \mathrm{mec} .13642$

Yates, M. C., Debes, P. V., Fraser, D. J., and Hutchings, J. A. (2015). The influence of hybridization with domesticated conspecifics on alternative reproductive phenotypes in male Atlantic salmon in multiple temperature regimes. Can. J. Fish. Aquat. Sci. 72, 1138-1145. doi: 10.1139/cjfas-2014-0527

Conflict of Interest Statement: The reviewer, JA, declared a past co-authorship with several of the authors, MH, MP, RG, AS, JL, ER, JL-B, US, to the handling editor.

The remaining authors declare that the research was conducted in the absence of any commercial or financial relationships that could be construed as a potential conflict of interest.

Copyright (C) 2019 Donfrancesco, Ciucci, Salvatori, Benson, Andersen, Bassi, Blanco, Boitani, Caniglia, Canu, Capitani, Chapron, Czarnomska, Fabbri, Galaverni, Galov, Gimenez, Godinho, Greco, Hindrikson, Huber, Hulva, Jedrzejewski, Kusak, Linnell, Llaneza, López-Bao, Männil, Marucco, Mattioli, Milanesi, Milleret, Mysłajek, Ordiz, Palacios, Pedersen, Pertoldi, Pilot, Randi, Rodríguez, Saarma, Sand, Scandura, Stronen, Tsingarska and Mukherjee. This is an open-access article distributed under the terms of the Creative Commons Attribution License (CC BY). The use, distribution or reproduction in other forums is permitted, provided the original author(s) and the copyright owner(s) are credited and that the original publication in this journal is cited, in accordance with accepted academic practice. No use, distribution or reproduction is permitted which does not comply with these terms. 